\title{
Profissionalização por gênero em escritórios paulistas de advocacia
}

\author{
Maria da Gloria Bonelli, Luciana G. Cunha, \\ Fabiana L. de Oliveira e Maria Natália B. da Silveira
}

Nas últimas décadas registra-se o aumento da participação feminina no total de portadores de título superior, ultrapassando o contingente masculino. Em 2003, dos 528.223 concluintes do terceiro grau no Brasil, 329.311 eram mulheres $(62 \%)^{1}$. A Pesquisa Nacional por Amostragem de Domicílios, PNAD 2005, encontrou 7.714.890 mulheres com ensino superior; para os homens esse número foi de 6.058 .704 (56\% a 44\%)2. Nota-se também o crescimento da presença delas no mercado de trabalho, concentrando-se nas carreiras identificadas como guetos femininos, voltados para os cuidados, as artes e as humanidades ${ }^{3}$.

$\mathrm{Na}$ advocacia, este fenômeno se confirma com o aumento dos registros profissionais de mulheres. A OAB nacional, em 2006, tinha 312.734 advogados e 248.085 advogadas (56\% a 44\%); a OAB-SP contava com 116.948 homens e 93.245 mulheres ( $56 \%$ a 44\%), sendo que nos últimos três anos o número de novas inscritas superou os novos inscritos, com 35.873 advogadas e 32.763 advogados $(52 \% \text { a } 48 \%)^{4}$.

Essas mudanças vêm se destacando na advocacia, e alterando sua configuração. $\mathrm{O}$ aumento expressivo na oferta de cursos superiores de direito ocorreu concomitante à ampliação da participação feminina nesses cursos e sua inserção no mercado das profissōes jurídicas. A expansão do ensino do

1. Consulta aos dados estatísticos sobre ensino superior no site www. inep.gov.br, 17/5/2007.

2. PNAD, 2005, IBGE.

3. Bruschini e Lombardi (2000) identificam o crescimento bipolar da participação feminina no mercado de trabalho brasileiro. Para elas, essa inserção é marcada pela formação de guetos de gênero, com as mulheres ocupando as áreas do "cuidar". As autoras mostram que o estereótipo sobre a falta de disponibilidade das mulheres para a dedicação à profissão cai por terra quando se focaliza a Enfermagem, 
cuja jornada é grande e envolve plantões noturnos.

4. Ver Barbalho (2008).

5. Esses dados foram extraídos de Junqueira (1999, p. 24), que os coletou no site da Martindale-Hubbell.

6. Ver Nelken e Feest (2001). direito, agora submetida a avaliaçôes mais criteriosas pelo Ministério da Educação, tem alimentado também uma maior profissionalização da docência na área, que vai se transformando em um novo segmento desse mercado de trabalho, com a busca de títulos de pós-graduação para habilitação acadêmica, atividade antes dominada pelos praticantes que obtinham alguma notoriedade no exercício profissional.

A advocacia até os anos de 1990 foi uma profissão liberal, exercida principalmente em escritórios de pequeno e médio porte. Nessa época, as sociedades de advogados no Brasil totalizavam noventa, e concentravam-se no ramo cível/societário. As que reuniam mais de cinqüenta advogados estavam localizadas em São Paulo e eram em número de seis; 17 escritórios no país tinham entre 26 e 50 advogados, e entre 11 e 25 advogados havia $67^{5}$ sociedades de advogados. Dados coletados em um survey realizado pela OAB em 1996 indicavam que 66\% dos advogados se consideravam no exercício tipicamente liberal da profissão, 50\% das advogadas estavam no exercício autônomo.

Ao boom dos cursos superiores e da participação feminina veio somar-se a efervescência econômica das privatizações de grandes empresas públicas, que ampliaram muito as especializações, em particular no direito empresarial, com os advogados encontrando novas atividades nas áreas de negócios. Escritórios pequenos conseguiram crescer no cenário da globalização econômica, precisando contratar mais advogados e advogadas para cuidar dos interesses jurídicos da clientela corporativa que se expandia, trazendo demandas especializadas, mas também muitas outras de caráter rotineiro e repetitivo.

Na década de 1990, no Brasil, houve um grande crescimento na área do direito empresarial. Esse fato está associado aos processos de privatizações de empresas públicas e de terceirizações. Muitas empresas na época deixaram de ter seus departamentos jurídicos e passaram a contratar escritórios de advocacia para tratar de questôes empresariais. O contexto internacional também influenciou diretamente o cenário brasileiro. Nesse processo de privatizaçôes, por exemplo, os Estados Unidos atuaram diretamente intensificando as transferências de modelos de instituiçôes e a adaptação de cultura jurídica ${ }^{6}$. Com isso, houve um impacto muito grande nas empresas e nos escritórios de advocacia no Brasil.

A organização do trabalho jurídico foi perdendo as características homogêneas como profissão exercida em escritórios individuais ou escritórios partilhados por colegas. A passagem dessa forma de organização para a das 
sociedades de advogados, estratificadas internamente entre sócios com participação nos resultados e associados com remuneração mensal, acompanhada da divisão social do trabalho, separando os conteúdos tradicionais das novas especializações, e o trabalho rotineiro daquele que busca maior expertise, foi facilitada pelo ingresso feminino na advocacia. Atualmente, o Centro de Estudos das Sociedades de Advogados, que articula e representa interesses dessas firmas de advocacia, conta com cerca de 400 sociedades filiadas, sendo 270 delas em São Paulo.

O modelo das sociedades de advogados é resultado da internacionalização da profissão, cada vez mais inserida nas relações de importação e exportação do conhecimento especializado entre países do norte e do sul, com a padronização transnacional de serviços jurídicos ${ }^{7}$. Nesses grandes escritórios, o profissional domina línguas estrangeiras, em especial o inglês, tem experiência de curso ou estágio no exterior, que é enfatizado em seu currículo divulgado na página da firma na internet, representa grandes empresas ou escritórios estrangeiros, chegando algumas dessas sociedades de advogados a ter filiais fora do Brasil. O tipo de prestação jurisdicional também muda, enfatizando-se o atendimento das necessidades em torno dos negócios dos clientes empresariais, o que com freqüência dispensa a ida para litigar no Fórum, como costumava ser a prática característica da profissão.

O sistema jurídico adotado no Brasil é o de Civil Law, comum na Europa Continental, em que o Estado tem um papel central na solução de conflitos que chegam ao Judiciário. O direito civil é inspirado no direito romano, no qual a fonte principal do Direito é a lei. Não por acaso o nosso sistema jurídico é um sistema organizado por meio da legislação e, mais especificamente, por códigos (código civil, código comercial, código penal etc.) ${ }^{8}$. Exatamente por isso, o ensino do direito no Brasil é, predominantemente, voltado para o ensino da lei e dos códigos, sendo que um processo de mudança para uma vertente que priorize o raciocínio empresarial envolve uma disputa simbólica. Esse fato tem uma forte influência na estruturação da profissão no país, com mudanças que permearam o campo do direito e as especificidades do caso brasileiro, relevantes para se pensar a questão da profissionalização de advogados e advogadas nos escritórios de São Paulo.

A feminização da carreira veio ao encontro dessas transformações, reduzindo as resistências às mudanças na forma tradicional de se exercer a advocacia no Brasil. A intensificação na divisão social do trabalho foi acompanhada da divisão sexual do trabalho, com as mulheres concentrando-se nas
7. Sobre essa internacionalização na América Latina, ver Dezalay e Garth (2002).

8. Dados extraídos do site http://www.ufrgs/ bioética, em 29/7/2007. Sobre a Common Law ver David (1996), Galindo (2004) e Barbalho (2008). 
9. O gênero é concebido como uma construção cultural e social. É uma categoria analítica que questiona a naturalização da dualidade sexual como constitutiva da essência fixa e imutável do ser. Para uma síntese das mudanças no conceito de gênero e a introdução de uma nova utilização para a categoria "mulher", ver Piscitelli (2002), e o segundo tópico deste artigo.

10. A pesquisa foi promovida pelo GVLaw, da FGV-SP e contou com o apoio do Centro de Estudos das Sociedades de Advogados Cesa. Os questionários foram aplicados em 2006.

11. Os grandes escritórios de advocacia organizaram-se a partir da criação do Cesa. A sociedade de advogado baseia-se no modelo norte-americano de estruturar a advocacia, com uma administração profissional. Em geral, ela estratifica os advogados (as) em sóciose associados. Os sócios comandam e controlam a participação no escritório, selecionando advogados para suas equipes, como associa- áreas tradicionais e nas atividades mais rotineiras, e os homens, naquelas mais especializadas e inovadoras.

O expressivo crescimento na participação feminina entre os jovens profissionais, concomitante à conquista de direitos por parte das mulheres, alimenta a percepção de que as oportunidades se equilibraram entre homens e mulheres na advocacia. Com isso, o cenário das diferenças no mundo profissional do direito no século XXI não seria o da discriminação de gênero", mas o da igualdade baseada no mérito, na dedicação e na competência. Várias profissionais bem-sucedidas nas grandes bancas afirmam essa mudança, entendendo que as carreiras que elas fizeram são evidências disto.

O objetivo deste artigo é identificar as tendências profissionais em escritórios e sociedades de advogados da cidade de São Paulo, observando quantitativamente as semelhanças e as diferenças entre os gêneros em uma amostra ${ }^{10}$ de 216 profissionais. $\mathrm{O}$ argumento é que o crescimento do número de advogadas está em consonância com a nova forma de organização do trabalho, que envolve a estratificação da profissão em sócios e associados, a divisão de tarefas rotineiras e de atividades especializadas, e de clientes empresariais e individuais. Ou seja, a passagem da forma tradicional de se organizar a profissão em escritórios onde predominava a atuação solo ou a parceria com um ou outro colega para o modelo das sociedades de advogados como firmas de advocacia, com os donos das bancas contratando os serviços de muitos advogados e advogadas. Apesar das conquistas das mulheres em termos de direitos, de qualificação e de posições no mercado de trabalho, a subordinação do feminino na vida privada transfere-se para a dimensão profissional, viabilizando a hierarquização da advocacia com custo emocional maior para as mulheres.

A amostra da pesquisa foi desenhada dentro da lógica de priorizar profissionais mais jovens, graduados a partir da década de 1990; com isso procuramos cobrir um período em que a expansão dos cursos de graduação em direito se configurava. Para determinar o tamanho da amostra trabalhamos com base na listagem de sociedades e escritórios filiados ao Centro de Estudos das Sociedades de Advogados - Cesa ${ }^{11}$. Outra fonte de apoio que utilizamos foi o livro comemorativo de 70 anos da OAB-SP, que possuía uma lista de escritórios de São Paulo. Juntando todas as listagens disponíveis, totalizamos 993 escritórios não filiados ao Cesa e 272 escritórios filiados. Tanto a OAB-SP como a Associação dos Advogados de São Paulo não autorizaram o acesso à base de dados de seus membros, o que impossibilitou utilizar tal universo para a extração da amostra. Do total de 1.265 
escritórios listados, optamos por trabalhar com uma amostra de 78 escritórios. Esses foram distribuídos da seguinte forma: escritórios de 1 a 9 advogados (pequeno), de 10 a 49 advogados (médio) e de 50 ou mais advogados (grande). No desenho inicial entrevistaríamos 36 escritórios na primeira faixa, 24 na segunda e 18 na terceira. Assim, a idéia era fazer com dois advogados em cada escritório pequeno, três em cada escritório médio e quatro em cada escritório grande. Outro ponto era seguir uma cota igual de homens e mulheres em cada faixa; esse recorte não reflete a participação efetiva de homens e mulheres no mercado de trabalho, mas favorece a identificação da pluralidade de concepções sobre as tendências profissionais. Enfrentamos algumas dificuldades em termos de listagem e resistência de escritórios em nos conceder entrevistas. A metodologia utilizada foi a de substituição de acordo com o perfil, ou seja, organizamos a listagem de forma aleatória e a cada recusa de um escritório procurávamos substituir pelo que vinha na seqüência e tinha o mesmo tamanho ou chegasse o mais próximo das características iniciais. O critério de distribuição igual de homens e mulheres não pôde ser seguido à risca dentro de cada escritório, uma vez que alguns escritórios não tinham homens e outros não tinham mulheres, mas conseguimos ficar dentro da cota inicial, nos 216 entrevistados que compõem a amostra utilizada neste artigo.

\section{Gênero, divisão sexual do trabalho e profissionalismo}

Inicialmente, a pesquisa teve a intenção de articular os conceitos de gênero e de profissionalismo no estudo dos jovens advogados e advogadas de São Paulo. Pretendia-se contrastar homens e mulheres no exercício profissional, em termos de oportunidades, barreiras e tendências na profissionalização. Entretanto, a bibliografia sobre gênero introduziu novas perspectivas e evidenciou os limites no trabalho de campo desenvolvido para este fim. A concepção de gênero embutida na definição da amostra estava associada à "diferença sexual", reduzindo o gênero como construção social à diferença sexual. Assim, a amostra induzia ao binarismo e ao determinismo biológico ao estratificar os informantes a partir de $50 \%$ homens e $50 \%$ mulheres, atrelando o gênero ao sexo. Um passo importante dado pela literatura da área foi o de tentar superar problemas na análise da subordinação social da mulher, gerados pela utilização de conceitos que essencializavam diferenças físicas para explicar a dominação masculina e a subordinação feminina. dos que recebem remuneração mensal pelo trabalho realizado. 
Nesse sentido, deu-se ênfase em mostrar como o gênero é uma construção social que procura fixar identidades a partir das diferenças percebidas entre os sexos, sendo também um modo de dar significado às relações de poder. As contribuições de Scott (1990) foram decisivas para a crítica à essência que se atribuía à diferença física entre homens e mulheres, universalizando a dominação masculina no tempo e no espaço, como também para destacar a dimensão relacional da categoria de gênero, não cabendo focalizar a mulher fora das relações sociais e culturais com outros homens e mulheres. O gênero como categoria analítica desconstruiu a concepção biologizada, mostrando como a diferença sexual é socialmente construída, em vez de ser a base da subordinação feminina. A autora evidenciou também como a segregação no mercado de trabalho é parte do processo de construção binária do gênero e das relaçôes de poder que engendravam.

A concepção binária de poder também foi criticada. No lugar de se entender o poder como exclusivo aos dominantes, e ausente no pólo dominado, adotou-se a noção foucaultiana de que o poder circula em uma perspectiva relacional, possibilitando às mulheres ter poder, mesmo que assimétrico ao dos homens, nas relações sociais (cf. Barbalho, 2008, p. 37).

No âmbito dos estudos que desnaturalizaram o sistema sexo/gênero e a subordinação da mulher, Rubin viu nas relações de parentesco a via de se exacerbar na cultura as diferenças biológicas entre os sexos. Assim, gênero resultaria da construção cultural resultante de relações sociais específicas, não se configurando em uma opressão invariável, e podendo ser modificado. Essas diferenças nas relações de poder entre homens e mulheres produziriam variações na dominação-subordinação, diferenciando, por exemplo, situações de controle efetivo de homens sobre mulheres, das situações decorrentes da divisão sexual do trabalho (cf. Piscitelli, 2002, p. 21).

Essa concepção contrasta com a de Bourdieu (1999) sobre a dominação masculina. Para ele, a subordinação feminina deve-se, em parte, a um processo de eternização do arbitrário, sendo preciso desvendar os processos ahistóricos de naturalização dessa posição secundária diante do homem. Essa eternização da dominação masculina é concebida como um modelo universal, embora Bourdieu aponte que a ação política de homens e mulheres pode modificá-la. A reprodução dessa dominação persiste mesmo com mudanças, como a atuação do movimento feminista, o aumento do acesso das mulheres ao ensino escolar e superior, o crescimento das mulheres no mercado de trabalho, a desvaloriação das tarefas domésticas e uma nova configuração familiar (crescimento no número de divórcios, de mães sol- 
teiras, entre outras). Porém, segundo o autor, a nova condição feminina continua a obedecer a lógica do modelo entre o masculino e o feminino, que é alimentada pelo habitus, sistema de disposiçōes adquiridas na socialização, que funcionam como organizadoras das práticas e das representações. A violência simbólica recorre às categorias androcêntricas, que se inscrevem nas coisas e nos corpos como estruturas duradouras para a eternização das relações de dominação, que são legitimadas na subordinação. $\mathrm{O}$ conceito de campo, em Bourdieu, traz a dimensão das lutas concorrenciais entre a ortodoxia e seu direito de dizer o que é direito, e a heterodoxia que a contesta. O feminismo como heterodoxia reproduz as posiçóes no campo de forças e de lutas, mantendo a dominação masculina como ortodoxia.

Outra abordagem sobre a distinção entre sexo e gênero foi elaborada por Butler (2003). Ela deu ênfase à cultura para distingui-los, contrastando sexo, como diferença biológica entre macho e fêmea, e gênero, como construção social, cultural e psicológica. As identidades fixas e essencializadas em "homens" e "mulheres" puderam ser discutidas, abrindo um leque de variações segundo a cultura e a experiência. Assim:

Ela propõe uma pesquisa genealógica, que, ao mostrar como foi construída a dualidade sexual, como diversos discursos científicos produziram essa dualidade discursivamente, desafie o caráter imutável do sexo (Piscitelli, 2002, p. 27).

Não só o gênero é culturalmente construído, mas o sexo também, superando o binarismo sexo-natureza, gênero-cultura. Nessa perspectiva, gênero deixa de se referir ao masculino e ao feminino, introduzindo múltiplas possibilidades de identificaçôes que não estão essencializadas em formas duais de diferença sexual e de gênero.

Para Butler, gênero e sexo não são "naturais", possuem significação cultural que se inscreve no corpo, mas muda no tempo e no espaço, não se reduzindo a oposições binárias simples. O gênero contém as relaçôes de poder que produzem o efeito de um sexo pré-discursivo, construído assim culturalmente. Essas relações sociais de poder desenvolvem-se em contextos específicos, não sendo permanentes. A discriminação e a desigualdade entre os sexos e os gêneros resultam de relaçôes de dominação que podem ser mudadas, e a desessencialização da subordinação da mulher contribui com isso.

Piscitelli (2002) sistematiza o contraste entre as categorias analíticas "gênero" e "mulher", mostrando que após a crítica desconstrutivista do conceito de gênero, autoras que se preocupam com a prática política das mulheres 
12. Ver a revisão da bibliografia sobre divisão sexual do trabalho, feita por Hirata e Kergoat (2003).

\section{O "script sexuado"} de progressão nas carreiras foi conceituado por Le Feuvre e Lapeyere (2005). Tal script pressupõe que os homens são competentes na esfera profissional não precisando demonstrar isso de antemão, enquanto as mulheres precisam provar que são capazes. Há o pressuposto que elas não têm disponibilidade total para o trabalho, atribuindo-se apenas às mulheres a conciliação da vida familiar e profissional. Oshomens ficam dispensados desta conciliação, constituindo o perfil desejado pelas firmas de dedicação integral à profissão.

14. Com o aumento no número de mulheres ingressando na $\mathrm{OAB}$, a tendência é esta proporção se inverter em breve. propõem a reelaboração dessa categoria, mas sem um sentido definido do que é mulher, sem atribuir-lhes uma essência, e situando-as em contextos específicos. Essa categoria reconheceria as diferenças entre as mulheres, mas identificaria as semelhanças que viabilizam um projeto político feminino.

Como a pesquisa de campo deteve-se no estudo de homens e mulheres na advocacia, sem aventar outras identificaçôes distintas da heterossexualidade, focamos a análise principalmente no âmbito da divisão sexual do trabalho $^{12}$. Partilhamos do insight de Scott de que a segregação no mercado é constitutiva das relaçóes sociais de gênero e das relações de poder entre eles, em vez de enquadrar as mulheres no espaço da casa, que chegam tardiamente ao mundo profissional. Trabalhamos com o conceito de gênero na dimensão relacional entre masculino e feminino, mas limitado ao aspecto binário heterossexual.

O profissionalismo, como uma ideologia e uma prática de monopolização de mercados, expandiu-se no final do século XIX e consolidou-se no século XX. Dessa forma, vem marcado pelas assimetrias nas relações de poder entre os gêneros ao longo desse período, mesmo que essas relaçóes experimentem mudanças quantitativas e qualitativas na atualidade.

O fechamento e a proteção de mercados, a neutralidade da expertise, as relações de confiança entre leigo e profissional, a especialização e a dedicação integral à profissão formam um conjunto de características que reproduzem a segregação sexual do trabalho. Por outro lado, as conquistas das mulheres em termos de direitos e espaço no mundo profissional superior abrem oportunidades de empoderamento, reduzindo a assimetria e a subordinação feminina.

\section{0 "script sexuado"13 das carreiras e as barreiras à ascensão das mulheres na advocacia brasileira e internacional}

Em um levantamento feito no site do Cesa, abarcando 20\% dos escritórios filiados da cidade de São Paulo, selecionamos cinqüenta sociedades de advogados, cujo quadro profissional totalizou 2.601 advogados(as). A Tabela 1 apresenta a distribuição dessa amostra, segundo o tamanho do escritório, a posição ocupada e o gênero. Os advogados sócios são 75\% e as advogadas sócias, $25 \%$, os advogados associados são $51 \%$ e as advogadas associadas, $49 \%{ }^{14}$. Quando classificamos essas sociedades em faixas, conforme o número de advogados(as), registramos uma barreira em todas as faixas para o ingresso de mulheres na condição de sócia. Os escritórios de médio 
porte, reunindo de 10 a 49 profissionais, apresentam maior participação de associadas (53\%), mas como sócias, as advogadas são 29\%. O ambiente menos receptivo é o modelo tradicional de escritório solo ou com poucos parceiros, onde os homens predominam com larga vantagem, como sócio (71\%) e associado (62\%), seguido das grandes sociedades de advogados (a partir de cinqüenta profissionais), com $76 \%$ de sócios e $48 \%$ de associados.

A literatura específica refere-se a essa barreira de gênero para o topo da profissão como "teto de vidro" (glass ceiling). Junqueira (1999) reporta-se ao estudo de Thornton (1996, apud Junqueira, 1999) sobre as mulheres nas profissões jurídicas na Austrália, como também a estudos focalizando a mesma temática em outros países, para pensar as especificidades e as semelhanças com o caso brasileiro. O teto de vidro é comum a todos. Refere-se à barreira invisível que dá a ilusão de igualdade de oportunidades na carreira, mas bloqueia o acesso às posições elevadas da hierarquia profissional, mantendo as advogadas nas atividades menos valorizadas, que não preparam para posiçôes de prestígio e poder, e têm pouco contato com clientes. Em países como os Estados Unidos, onde a inscrição da mulher na ordem dos advogados (bar association) só foi permitida a partir da década de 1970, alguns autores relacionam o teto de vidro com este ingresso tardio, o que seria superado com o tempo. Mas, esse obstáculo existe nas mais variadas carreiras que incorporaram a participação feminina em diversos países de origens e tradições distintas. Tal bloqueio não pode ser superado apenas pelo tempo, sem mudanças na distribuição desigual de poder profissional. E esta não será modificada sem transformações nas relaçôes entre homens e mulheres no âmbito da casa.

Uma outra fonte recente sobre o perfil dos profissionais da advocacia no Brasil é a Relação Anual de Informações Sociais - Rais, de 2005. Esses dados são fornecidos por empresas e órgãos públicos, ao Ministério do Trabalho, sobre seu quadro de emprego formal (assalariados), o que não se aplica aos sócios(as) e associados(as) dos escritórios e das sociedades de advogados. Mesmo assim, permite visualizar as desigualdades de gênero no mercado de trabalho jurídico. Os resultados a seguir foram extraídos do subgrupo 241 [advogados(as), procuradores(as), tabeliães(ãs) e afins] da Rais, e encontram-se na Tabela 2.

No total de 51.551 profissionais do direito, 45\% são mulheres, e elas são mais jovens do que eles. As advogadas até 39 anos de idade eram 66\% do contingente feminino. Para eles, essa proporção era de 52\%, o que confirma a expansão mais recente das mulheres nessas ocupações. Quanto ao 
número de horas trabalhadas, as advogadas apresentam uma carga semelhante à dos advogados. Até 30 horas semanais, há $16 \%$ delas e $18 \%$ deles, na faixa 30-40 horas semanais, há $46 \%$ delas e $44 \%$ deles, e na faixa $41-44$ horas semanais, elas são $39 \%$ e eles, $38 \%$. Nessas posiçōes, as mulheres não apresentaram maiores dificuldades de cumprir uma carga horária equivalente e até superior à dos homens, mas a faixa de remuneração média é mais baixa para elas. É provável que para os homens haja mais articulação deste trabalho com a prática da advocacia em escritório.

Entre os advogados e afins, a distribuição da remuneração é a seguinte: $46 \%$ até 10 salários mínimos, $25 \%$ de 10,1 a 20 salários mínimos e $29 \%$ ganham mais de 20 salários mínimos. Para as advogadas e afins é: $48 \%$ até 10 salários mínimos, $27 \%$ de 10,1 a 20 salários mínimos e $25 \%$ recebem mais de 20 salários mínimos. A naturalização do pressuposto de que as mulheres dedicam menos tempo ao trabalho por "preferirem" combinar a jornada profissional com a jornada da família não se confirma nesses dados. Aqui o "teto de vidro" deixa ver que o princípio da remuneração igual para trabalho igual também não se aplica à atividade.

No mercado "liberal" da advocacia no Brasil, os escritórios de médio porte são os que mais contam com a participação de advogadas, mas em posições assalariadas. $\mathrm{Na}$ condição de sócia, elas ocupam espaço semelhante nos escritórios pequenos e médios (29\%). Analisando as mulheres na advocacia holandesa, Groot-van Leeuwen (2003) encontrou maior dificuldade de inserção da advogada nos escritórios de pequeno porte, e atribuiu isto à predominância de uma visão tradicional sobre as diferenças de gênero que seriam mais acentuadas nesses escritórios.

A concentração das advogadas nas posiçôes menos valorizadas da carreira e nos escritórios médios é interpretada tanto como um preconceito das firmas, que partem do estereótipo de que as advogadas não têm disponibilidade para o grau de dedicação exigido e precisam provar sua competência prejulgamentos que não se aplicam aos advogados -, quanto como resultado de um "script sexuado". Nele, a conciliação da vida familiar e profissional é atribuição exclusivamente feminina e a pressuposição da competência na esfera profissional é monopolizada pelos homens (cf. Le Feuvre e Lapeyere, 2005, p. 113). A indisponibilidade masculina na esfera doméstica combinase com a "escolha" das mulheres por trabalhos que lhes permitam usufruir de soberania sobre seu tempo, e de exercê-lo em locais que lhes sejam menos hostis, o que explicaria em parte a sub-representação feminina nas posições privilegiadas no mercado profissional, fator que incide sobre a remuneração 
obtida. Segundo as autoras, esse "script sexuado" também segrega internamente as profissōes jurídicas no que se refere à especialização e à oferta equilibrada de serviços jurídicos pelo território. Para elas, a sub-representação das mulheres no exercício profissional é preocupante, porque as advogadas ultrapassarão o número de homens no exercício da advocacia e "não representam mais do que uma pequena minoria de indivíduos eleitos para refletir sobre as transformações estruturais em curso e para elaborar as estratégias de defesa dos interesses da profissão no futuro" (Idem, p. 122).

Vários são os fatores que beneficiam os advogados em detrimento das advogadas no processo de profissionalização. O capital social é o primeiro deles. Segundo Schultz e Shaw (2003), o capital acadêmico é partilhado por ambos os gêneros, mas a entrada na profissão e a progressão nela dependem do acesso a grupos hegemônicos de poder que atuam como mentores e notáveis. Como as mulheres estão menos posicionadas no topo da profissão, elas têm mais dificuldade de constituir essas redes. Além disso, chegar até a posição de sócio requer capital social para recrutar novos clientes empresariais e debitar mais horas de serviços prestados. $\mathrm{O}$ caminho até lá passa pela sociabilidade em práticas que consolidam vínculos de masculinidade, como formar times de futebol, sair para beber com os colegas, conversar sobre esportes, jantar com clientes, entre outras atividades que compõem o diferencial de gênero não acessível às advogadas. O capital social feminino também é escasso nas funções de representação nas associações profissionais, constituindo um perfil profissional mais desfavorecido desses atributos.

Sendo o impacto do gênero tão forte para estratificar a carreira, as mulheres que conseguem superar as barreiras de ingresso como sócias são aquelas que melhor realizam o apagamento dessas diferenças, e o discurso sobre a conquista da igualdade de oportunidades é uma das formas de fazê-lo. Aceitar o "desafio" de ter que provar ser tão capaz quanto os homens é o outro lado da mesma moeda que busca tornar o gênero invisível.

O profissionalismo construído no final do século XIX e início do século $\mathrm{XX}$ - contexto que reservava a rua, o público e a expertise para os homens, e a casa, o privado e o leigo para as mulheres - incorpora as advogadas divididas pela forma como lidam com o gênero. Aquelas que conseguem superar a barreira para se tornarem sócias são também as bem-sucedidas na realização do trabalho ideológico e de administração das emoções ${ }^{15}$ no sentido de ajustarem-se aos valores masculinos da profissão. A "igualdade" de oportunidades só parece alcançável quando é operada a masculinização do ideário e da prática profissional.
15. Arlie Hochschild conceituou o trabalho emocional como a forma consciente pela qual as pessoas atuam para suprimir a distância entre o que estão sentindo e o ideal que têm do que deveriam sentir, submetendo os sentimentos à manipulação e a serem administrados, muitas vezes assumindo a característica de uma jornada de trabalho extra. Os subalternos realizam mais trabalho emocional que os dominantes, assim as mulheres fazem mais do que os homens. Ver Bonelli (2004). 
Devido à limitação de espaço, este texto vai se deter na análise dos dados quantitativos obtidos no survey, para estabelecer a base objetiva das semelhanças e das diferenças entre homens e mulheres na advocacia, deixando a discussão do material qualitativo para outro momento.

\section{Os resultados do survey: tendências profissionais nas sociedades de advogados"}

Com o intuito de identificar o perfil dos advogados e das advogadas, a amostra estabeleceu cotas de $50 \%$ para cada grupo. Como se trata de um grupo jovem, os(as) solteiros(as) formam o contingente principal (63\% dos entrevistados e 59\% das entrevistadas), mas há entre as mulheres alguns poucos casos de uniões desfeitas. A distribuição etária indica que os advogados da amostra são um pouco mais jovens do que as advogadas, com $72 \%$ deles e $67 \%$ delas tendo de 23 a 30 anos. Entre 31 e 40 anos, há 25\% deles e $31 \%$ delas. Esses dados contrastam com os obtidos na Rais.

Os períodos nos quais os(as) informantes se graduaram são exatamente iguais para ambos: 37\% entre 1991 e $1999,55 \%$ entre 2000 e 2004, e $8 \%$ entre 2005 e 2006 . A cor é outro aspecto comum: o grupo é esmagadoramente branco ( $96 \%$ para eles e $98 \%$ para elas).

A amostra revela-se proveniente de uma origem social elevada em ter-

16. O fato de a amostra ter sido extraída principalmente dos escritórios filiados ao Cesa pode ter elevado a composição social do grupo, já que as sociedades de advogados são reconhecidas como firmas mais elitizadas. mos de escolaridade ${ }^{16}$. A instrução paterna predominante é o curso superior completo para $78 \%$ dos jovens advogados e é de 69\% para as advogadas. Tendo o pai com o segundo grau completo ou universitário incompleto há 15\% dos homens e 19\% das mulheres. Embora haja uma concentração menor de mães formadas em faculdades, o grupo preserva o padrão de uma origem social bem instruída, com 60\% dos advogados e 55\% das advogadas oriundos de famílias nas quais a mãe possui diploma universitário. $\mathrm{O}$ segundo grau e o superior incompleto reúnem 29\% das mães deles e 35\% das mães delas. Embora o grupo dos rapazes apresente famílias com mais anos de estudo, sobressai a semelhança entre os gêneros na alta escolarização dos pais. Em sintonia com esses dados, observa-se que 52\% dos homens possuem parentes que atuam na área jurídica, sendo $44 \%$ como advogados. Para as mulheres, $48 \%$ possuem parentes na área jurídica, sendo $40 \%$ como advogados. A endogenia na carreira é grande na amostra, sendo maior para os entrevistados.

Detalhadas as semelhanças de perfil social entre os advogados e as advogadas, vamos examinar as características profissionais. 
Nesse aspecto, houve uma intencionalidade na seleção da amostra, procurando-se contemplar a variação no tamanho dos escritórios. Uma das formas de se fazer isso foi buscar entrevistar advogados(as) trabalhando em bancas filiadas ou não ao Centro de Estudo das Sociedades de Advogados.

Dividimos os escritórios em três faixas: pequenos, respondendo a 54 questionários; médios, com 92 questionários; e grandes, com 70 questionários. Na Tabela 3, vemos que na nossa amostra a primeira faixa é a que apresenta menor participação feminina ( $23 \%$ a $27 \%)$, seguida da terceira faixa (28\% a 37\%). As mulheres predominam apenas nos escritórios de 10 a 49 profissionais (36\% a 49\%), dados que estão em consonância com a amostra extraída do site do Cesa. Todas as sociedades de advogados classificadas na terceira faixa (50 profissionais ou mais) eram filiadas ao Cesa. As sociedades de advogados, sempre que podem, priorizam a advocacia de negócios e a clientela empresarial.

Se agruparmos os escritórios segundo a filiação ou não ao Cesa (Tabela 4), observamos uma incidência de advogadas nas sociedades que não compõem o quadro da associação. Ou seja, os escritórios filiados ao Cesa apresentam uma composição de $49 \%$ de advogadas e $51 \%$ de advogados, e esta proporção se inverte para as firmas não filiadas, onde as mulheres profissionais ultrapassam o número de homens. Disto resulta que os escritórios de médio porte, não filiados ao Cesa, são mais receptivos à participação de advogadas, bem como são percebidos por elas como lugares possíveis de se combinar a profissionalização e a vida privada, conforme o "script sexuado" (cf. Le Feuvre e Lapeyere, 2005).

Segundo as autoras é parte das diferenças nesse script os advogados planejarem se dedicar intensamente à carreira por alguns anos, para que isso resulte em um diferencial que lhes permita alcançar uma posição que mais tarde representará contar com advogados trabalhando com/para ele, o que lhe permitirá usufruir lazer. Para os homens, esse roteiro não inclui atividades na vida doméstica. Para as mulheres, ele combina trabalho que dê tempo à família, mas não prevê lazer. Sociedades de advogados regidas pela lógica empresarial e da disponibilidade total favorecem o script masculino e excluem o feminino. Nelas, o tempo médio para as advogadas obterem promoções é superior ao dos homens.

Mesmo em uma amostra jovem, ressalta-se a disparidade entre os gêneros no que diz respeito ao cargo ocupado. Conforme a Tabela 5, entre sócios de escritórios encontramos $34 \%$ de advogados e $20 \%$ de advogadas entrevistados, isto para um grupo que apresentou exatamente a mesma dis- 
tribuição em relação ao período em que se graduaram. Em função desta dificuldade de ingresso no topo da carreira, há um número maior de mulheres na posição de advogada sênior/plena (37\%) do que de advogado sênior/pleno (33\%). Já como advogada jr. as mulheres predominam sobre os homens ( $42 \%$ a $32 \%)$.

A Tabela 6 apresenta algumas informações que diferem daquelas observadas nos dados coletados no site do Cesa e em pesquisas internacionais. Embora nossa amostra não tenha sido aleatória, e não represente o grupo como um todo, ela capta tendências entre os mais jovens. As mulheres predominam nos escritórios de médio porte em posiçôes subordinadas, mas observase uma menor resistência à participação delas nos escritórios pequenos como associadas. É nesta faixa também que as advogadas estão constituindo suas próprias bancas advocatícias, apoiadas em sua reputação profissional.

Quanto às áreas, os advogados entrevistados declararam atuar em um número maior de especialidades do que as advogadas. Em média elas se referiram a duas áreas, e eles chegam perto de três áreas. Apenas em uma área as mulheres pontuaram mais do que os homens, no direito do trabalho. Os homens aparecem em porcentagem superior nas seguintes especialidades: contencioso, societário, comercial, penal, civil, tributário, administrativa e em novas áreas. Os profissionais de ambos os gêneros aparecem relativamente empatados nas áreas de direito de família, direito público, direito difuso e direito de negócios. As áreas mais mencionadas pelos homens são: contencioso, civil e comercial; pelas mulheres são: contencioso, civil e trabalho.

Nas pesquisas internacionais, as mulheres também tendem a ser menos especializadas do que os homens e a ocupar guetos femininos, como o Direito de Família. O que há de comum a tais guetos é que predomina o perfil do cliente individual - em vez do empresarial -, proveniente de estratos sociais médios e baixos, com menor retorno financeiro e maior trabalho emocional. A "opção" das advogadas por essas áreas está vinculada à administração da carga de trabalho profissional e familiar. São áreas que lidam com menos imprevistos e com tarefas rotineiras, cuja carga é ajustável ao planejamento de horário e tempo, envolvem menos especialização, treinamento e atualização (cf. Schultz e Shaw, 2003). Essas características reforçam a desvalorização do capital social das advogadas.

Outro fator de diferença de gênero na amostra é a instituição onde os informantes se graduaram (Tabela 7). Para as advogadas, há concentração nas faculdades privadas religiosas, com $50 \%$ delas formadas na PUC e no 
Mackenzie, proporção que para os advogados é de 40\%. Com diploma de universidades públicas elas constituem 19\% e eles, 29\%. Nas privadas leigas há empate com $31 \%$.

Há 77\% de entrevistados cursando ou tendo algum curso de especialização/pós-graduação, para 67\% delas. Para ambos, esses cursos são principalmente custeados pelo próprio profissional. O “script sexuado” também atua aqui. Há mulheres que interrompem os estudos em função da vida doméstica e retomam depois. Isto pode explicar a faixa etária feminina ser um pouco superior à masculina, mesmo que ambos os gêneros tenham se graduado no mesmo período.

Esse script se faz sentir nas possibilidades de realizar cursos de especialização e pós-graduação. A disponibilidade integral masculina para os assuntos da carreira é acompanhada da indisponibilidade para as questôes da vida doméstica. $\mathrm{O}$ montante de homens e mulheres casados na amostra é equivalente, mas há incidência de cursos de especialização e pós-graduação para eles. Esse fenômeno também é observado nas carreiras jurídicas públicas. Barbalho (2008) menciona o depoimento de juízas que destacam as diferenças nas oportunidades para a realização de pós-graduação, com elas acumulando as funções da família e os juízes avançando em sua titulação.

Quando indagados sobre os motivos para fazerem os cursos freqüentados, os advogados pontuaram mais do que elas nas seguintes alternativas: ascensão na carreira (48\% a 38\%), dedicação à área acadêmica (45\% a $32 \%)$, mudança na área de atuação (7\% a 5\%), ampliação dos horizontes (7\% a $1 \%)$, satisfação pessoal ( $2 \%$ a 0$)$ e prestígio junto ao cliente $(1 \%$ a $0)$. As advogadas pontuaram mais do que eles nas seguintes alternativas: melhorar currículo (39\% a 37\%), aperfeiçoamento pessoal (6\% a $2 \%$ ), atualização ( $6 \%$ a $1 \%)$, aprofundamento do conhecimento (4\% a $2 \%)$. As alternativas que destacam as possibilidades de alcançar sucesso profissional aparecem principalmente para os homens, já as que enfatizam um diferencial na competência foram mais mencionadas pelas mulheres.

Homens e mulheres também avaliam de forma diferente as áreas promissoras na advocacia. Elas aparecem à frente na avaliação positiva do direito tradicional ${ }^{17}$ (38\% a 26\%). Eles pontuam mais do que as advogadas ao considerar o direito de negócios ${ }^{18}$ promissor (51\% a 46\%), seguido do direito difuso ${ }^{19}(44 \%$ a $40 \%)$, do direito público ${ }^{20}$ (32\% a $\left.30 \%\right)$, das novas áreas $^{21}(40 \%$ a $19 \%)$ e da solução alternativa de disputas ${ }^{22}$ (16\% a 13\%). As mulheres vêem mais espaço a conquistar na área do direito tradicional que começa a desinteressar os homens, orientados para as especializações mais
17. Engloba principalmente as áreas de direito civil, trabalho, penal, família e tributário.

18. Inclui direito societário, empresas, negócios e antitruste.

19. Inclui direito ambiental, consumidor e direitos humanos.

20. Inclui direito internacional, constitucional, administrativo, fiscal e previdenciário.

21. Inclui direito na internet, eletrônico, das comunicações, desportivo e propriedade intelectual.

22. Inclui ADR (Alternative Dispute Resolution), mediação e arbitragem. 
recentes. Um padrão observado na feminização das carreiras é o fato de as mulheres ampliarem sua participação em áreas que os homens estão se retirando, o que reforça a segregação sexual do trabalho.

Quanto à remuneração (Tabela 8), até $\mathrm{R} \$ 4.000,00$ ganham $54 \%$ das advogadas e 39\% dos advogados da amostra. São os escritórios com até 9 profissionais que concentram a maior parte dos salários nas faixas mais baixas ( $64 \%$ delas e $59 \%$ deles). Mas, a maior disparidade nos rendimentos entre os gêneros está nos escritórios de 10 a 49 profissionais: neles 53\% das mulheres ganham até $R \$ 4.000,00$ e apenas $26 \%$ dos homens recebem este valor. Nas sociedades com 50 ou mais profissionais, a maioria dos(as) informantes ganha acima desse valor: $47 \%$ das advogadas e $37 \%$ dos advogados recebem mensalmente até $\mathrm{R} \$ 4.000,00$. Ou seja, onde as mulheres configuram-se como maioria, podendo se considerar um ambiente profissional receptivo a elas é onde a subordinação feminina e a desigualdade de remuneração com os homens são mais acentuadas.

Há concordância de opinião entre os entrevistados sobre o fator que é mais importante para o sucesso das sociedades de advogados: o consenso entre os gêneros é a "capacidade de conquistar novos clientes", seguido do "investimento na formação do corpo profissional". Esses aspectos aparecem na frente de outros, como o "sucesso nos tribunais", "notoriedade dos sócios", "administração da sociedade", "especialidade na área de atuação" e "investimento na estrutura do escritório". Os aspectos considerados menos relevantes foram: "número de sócios do escritório", "existência de metas de produção", "diversidade na área de atuação" e "existência de planos de carreira".

A opinião é homogênea também sobre os fatores mais importantes para ser bom profissional: lidera a lista a alternativa "boa comunicação com o cliente" acompanhada de perto por "conhecer a lei". Elas obtiveram pontuação mais elevada que "conhecer técnica processual", "conhecer a realidade política, econômica e social brasileira", "conhecer a realidade política, econômica e social mundial", "apresentar diversas soluçôes, entre elas jurisdição estatal" e "ter formação interdisciplinar".

A centralidade do mercado combinada com a expertise está assimilada tanto pelos pequenos, médios e grandes escritórios como por advogados e advogadas. Hoje, faz parte do ideário profissional da advocacia no Brasil colocar o cliente em primeiro lugar, principalmente quando ele é uma empresa. Isso é mais importante do que ter sucesso nos tribunais, porque os serviços prestados a essa clientela nem sempre envolvem a prestação jurisdicional. 
A expansão das sociedades de advogados, com as privatizações nos anos de 1990, deu mais fôlego a um modelo de organização profissional que já vinha crescendo no país. A predominância dos escritórios de pequeno porte persiste quantitativamente, mas o impacto das grandes firmas de advocacia modificou a profissão, estratificando-a a partir do tipo de clientela que atende: os pequenos concentram-se nos clientes individuais e os grandes priorizam as empresas.

Analisando a estrutura social da ordem de advogados de Chicago (Chicago Bar Association), Heinz e Laumann (1982) destacam o impacto dessa divisão do grupo profissional, constituindo dois hemisférios bastante distintos quanto à forma de organização interna, à identificação e ao ideário profissional. As sociedades de maior porte recrutam seus membros nas escolas de elite e tem por clientela as corporações; os escritórios menores recrutam profissionais em escolas de menos prestígio e representam indivíduos. Segundo Schultz e Shaw:

A homogeneidade da profissão jurídica sofreu uma erosão séria. Esse processo de fratura parece ser incontornável. É o inevitável resultado da exposição das sociedades de advocacia às forças de mercado e dos advogados às demandas de clientes poderosos na indústria, conforme a profissão vai passando pela transformação de ter orgulho de possuir uma ética de profissão liberal para uma empresarial, trabalhando sobre princípios puramente comerciais (2003, p. 53).

$\mathrm{Na}$ amostra entrevistada, observa-se a preponderância do modelo hierarquizado das grandes firmas, difundindo a estratificação da carreira em sócios e associados para todos os escritórios, a orientação para o mercado e a concorrência para conquistar novos clientes. O recrutamento de profissionais segundo o prestígio da escola não se encontra tão demarcado aqui, havendo, portanto, a possibilidade de se cruzar a "linha do equador" que separa os hemisférios dos grandes e dos pequenos escritórios ${ }^{23}$. Um exemplo disso é que do total de formados nas faculdades públicas, $48 \%$ estavam em sociedades de 50 ou mais advogados, 33\%, em sociedades de 10 a 49 advogados, e 19\%, em escritórios de um a nove profissionais. Como indica a Tabela 9, sendo a amostra mais jovem, raros são os casos que chegaram às posições mais cobiçadas, como a de sócio num grande escritório.

Consistente com os dados sobre o estudo dos advogados de Chicago, as escolas de elite fazem diferença para a entrada na carreira nos escritórios de maior porte, assim como para os profissionais alcançarem a posição de só-
23. Heinz e Laumann (1982) destacam que a bifurcação da carreira pelo tipo de cliente é acompanhada do recrutamento profissional distinto, não se cruzando a "linha do equador" que separa os dois hemisférios da advocacia norte-americana. 
cio nos escritórios médios. Mas os provenientes das escolas leigas (faculdades de direito que expandiram muito no boom do ensino superior) distribuem-se por todos os tipos de escritórios, com maior incidência nos pequenos e médios. Os graduados nas universidades religiosas concentram-se nos escritórios médios, apontando para uma correspondência entre o ranking das escolas e das sociedades de advogados. Como as escolas privadas são pagas, e isto envolve capital econômico e social, é possível se encontrar jovens bem-nascidos, que cursaram escolas menos prestigiadas, convertendo o capital social em capital profissional para ingresso nas sociedades de advogados de parentes ou conhecidos.

Registra-se também a formação de redes de recrutamento ligando gênero, tipo de escola e tamanho do escritório, sendo bem visível para as mulheres formadas nas universidades religiosas, que constituem o principal contingente de advogadas associadas dos escritórios médios.

\section{Considerações finais}

Os dados do survey indicam que a estratificação da carreira em sócios e associados e da prática em pequenos escritórios, para as médias e grandes sociedades de advogados, foi amortecida pelo ingresso das mulheres na advocacia. Essa bifurcação que dividiu a profissão em dois hemisférios, como apontam Heinz e Laumann (1982), ou a fratura que provocou uma séria erosão no grupo profissional, como analisam Schultz e Shaw (2003), não se apresenta tão acentuada em São Paulo. O processo de feminização dos escritórios médios faz a ponte entre os dois pólos. Estas sociedades de advogados espelham-se nas grandes firmas, difundindo o modelo de organização profissional dos escritórios, filiando-se ao Cesa, partilhando a mentalidade dos negócios e mantendo em sua carteira clientes empresariais. Baseados no "script sexuado", esses escritórios hierarquizam-se em seu interior, principalmente em associadas e sócios, com o "teto de vidro" a bloquear a passagem de uma posição à outra. As advogadas são contratadas para as funções rotineiras, menos especializadas e com remuneração inferior, muitas vezes tornando o orçamento elaborado pelo escritório mais competitivo perante a concorrência, o que facilita a conquista de clientes. A reputação profissional das mulheres é mais reconhecida nos escritórios pequenos quando montam suas próprias bancas, ou nas grandes sociedades quando realizam mais intensamente o trabalho emocional de apagamento do gênero. 
Esse é o dilema da profissionalização das mulheres nas carreiras masculinizadas. Quando elas alcançam posições de poder capazes de influenciar nas políticas profissionais, fazem-no procurando tornar o gênero invisível no trabalho. Aquelas que têm filhos vivem os custos da jornada dupla profissional e doméstica, com a taylorização do tempo destinado à família, e o desempenho de uma terceira jornada de trabalho composta da difícil administração dessas ambigüidades, acompanhada de estresse, estranhamento de si e perda da capacidade de sentir (Hochschild apud Bonelli, 2004).

Quando a administração das emoções é menor e o "script sexuado" é visível, a subordinação feminina ocupa o centro do palco, com as mulheres assumindo posiçôes desprestigiadas na carreira, desprovidas de capital social e reputação profissional, sem os recursos de poder capazes de influenciar mudanças nessa configuração. Embora o ingresso no mercado profissional seja visto como uma conquista pelas mulheres, principalmente quando comparado com a desvalorização do trabalho doméstico, a profissionalização por si só não é capaz de modificar a subordinação das relações de gênero na casa e na rua, embora possa torná-las menos assimétricas.

Assim, o impacto do ethos profissional sobre o gênero revela-se mais acentuado do que os reflexos do feminino sobre o profissionalismo, principalmente porque a participação das advogadas está represada nas posiçóes de menor prestígio e poder da carreira. Entretanto, a presença delas nos escritórios muda o cotidiano e influencia a sociabilidade no meio profissional, tornando o grupo mais plural. Transformaçôes mais significativas dependem do empoderamento das advogadas, o que compõe um leque diversificado de situações, desde elas sentirem que conquistaram segurança em um ambiente profissional antes hostil até ocuparem posições de poder capazes de influenciar os destinos da profissão. A expansão numérica ajuda nisso. Com metade do corpo profissional sendo composto de mulheres, a hostilidade tende a se atenuar, como o aumento na participação das advogadas nos pequenos escritórios indica. Também constituindo uma base eleitoral expressiva, a Ordem dos Advogados terá de formular políticas para elas, visando à ampliação de direitos e à eqüidade. Em vez de seguirem invisíveis no código de ética, as relaçôes profissionais precisariam ser regulamentadas para a redução da discriminação de gênero na profissão.

Se a subordinação feminina na carreira pode ser modificada, ela requer que a conciliação da vida familiar e profissional deixe de ser praticada apenas pelas mulheres e seja assumida também pelos homens. A esfera profissional não se isola dessas relações, já que o âmbito privado fornece parte do 
24. Sobre as possibilidades de emancipação das mulheres nesse período da vida, ver conferência de Thomas Leithäuser (2007). imaginário social do "script sexuado" que se pratica no mundo do trabalho. Há projetos políticos das advogadas articulando a mudança nesse roteiro tradicional de progressão na carreira, como existem também os projetos para sua conservação.

Embora se verifique o peso do apagamento do gênero para a superação das barreiras profissionais, favorecendo a perpetuação da dominação masculina (Bourdieu, 1999), há mulheres na carreira cujo cotidiano profissional já não se encontra sujeito às mesmas disposições. Em geral, a partir dos 50 anos as advogadas já consolidaram sua reputação profissional, aumentaram seu capital social, foram se liberando das responsabilidades de criação dos filhos, estão economicamente independentes, várias vivem separadas ou são solteiras, o bem-estar do corpo tem outros significados além de despertar atração física, a sociabilidade e o lazer são partilhados com outras mulheres, constituindo um dia-a-dia autônomo em relação às principais características que perpetuam a dominação de gênero. Se há um habitus que reitera o lugar feminino subordinado, esse quadro introduz a possibilidade de emancipação ${ }^{24}$.

Esse perfil reúne condições objetivas que tornam provável o impacto qualitativo da influência feminina nas transformações em curso na advocacia, tanto por acumular poder profissional e reconhecimento dos(as) colegas como por ser uma referência emancipada para gerações mais jovens. Aí reside a oportunidade da via de mão dupla simétrica entre as mulheres e a profissão.

TABELA 1

Distribuição dos Advogados e Advogadas de Escritórios de Advocacia Filiados ao Cesa, Segundo o Tamanho do Escritório e a Posição Ocupada.

\begin{tabular}{|c|c|c|c|c|c|c|}
\hline \multirow[b]{3}{*}{$\begin{array}{l}\text { SOCIEDADES } \\
1 \text { A } 9 \text { ADVOGADOS }\end{array}$} & \multicolumn{3}{|c|}{ Sócios } & \multicolumn{3}{|c|}{ Associados } \\
\hline & HOMENS & MulHeres & TOTAL & HOMENS & MulHeres & TOTAL \\
\hline & $71,1 \%$ & $28,9 \%$ & 45 & $61,7 \%$ & $38,3 \%$ & 47 \\
\hline $\begin{array}{l}\text { SOCIEDADES } \\
10 \text { A } 49 \text { ADVOGADOS }\end{array}$ & $71,2 \%$ & $28,8 \%$ & 125 & $46,6 \%$ & $53,4 \%$ & 451 \\
\hline $\begin{array}{l}\text { SOCIEDADES } \\
50 \text { ADVOGADOS OU MAIS }\end{array}$ & $76,5 \%$ & $23,5 \%$ & 371 & $52,2 \%$ & $47,8 \%$ & 1562 \\
\hline
\end{tabular}

Fonte: www.cesa.org.br. 
TABELA 2a

Faixa Etária de Acordo com Sexo

\begin{tabular}{l|c|c|c|c|c|c|c|c}
\hline \multirow{2}{*}{ SeXo } & \multicolumn{10}{c}{ FAIXA Etária } \\
\cline { 2 - 10 } & Até 17 & 18 a 24 & 25 a 29 & 30 a 39 & 40 a 49 & 50 a 64 & $65+$ & Ignorado \\
\hline FEMININO & 1 & 1.100 & 5.988 & 8.324 & 5.104 & 2.611 & 194 & 0 \\
MASCULINO & 9 & 954 & 5.169 & 8.557 & 6.959 & 5.595 & 984 & 2 \\
\hline
\end{tabular}

Fonte: Rais, 2005 (subgrupo 241 [advogados, procuradores, tabeliōes e afins]).

TABELA $2 \mathrm{~b}$

Horas Contratuais por Pemana e Faixa Salarial, de Acordo com Sexo

\begin{tabular}{l|c|c|c|c|c|c}
\hline SEXo & \multicolumn{5}{|c}{ FAIXA DE HORAS CONTRATUAIS POR SEMANA } \\
\hline \multirow{3}{*}{ FEMININO } & Até 12 hs. & 13 a 15 hs. & 16 a 20 hs. & 21 a 30 hs. & 31 a 40 hs. & 41 a 44 hs. \\
\cline { 2 - 7 } MASCULINO & 249 & 21 & 844 & 2.543 & 10.661 & 9.004 \\
\hline
\end{tabular}

Fonte: Rais, 2005 (subgrupo 241 [advogados, procuradores, tabelióes]).

TABELA 2c

Faixa Salarial de Acordo com Sexo

\begin{tabular}{|c|c|c|c|c|c|c|c|c|c|c|c|c|c|}
\hline \multirow[t]{2}{*}{ SEXO } & \multicolumn{13}{|c|}{ Faixa De Remuneraçāo Média Em Salário Mínimo } \\
\hline & Até $1 / 2$ & $1 / 2$ a 1 & +1 a 1,5 & $+1,5$ a 2 & $+2 \mathrm{a} 3$ & $+3 a 4$ & $+4 a 5$ & $+5 a 7$ & $+7 a 10$ & +10 a 15 & +15 a 20 & +20 & Ignorado \\
\hline FEMININO & 9 & 109 & 409 & 465 & 1.004 & 1.367 & 1.476 & 2.811 & 3.572 & 3.961 & 2.302 & 5.778 & 59 \\
\hline MASCULINO & 17 & 144 & 479 & 529 & 1.194 & 1.625 & 1.772 & 3.306 & 3.887 & 4.326 & 2.838 & 8.048 & 64 \\
\hline
\end{tabular}

Fonte: Rais, 2005 (subgrupo 241 [advogados, procuradores, tabeliōes]).

TABELA 3

Perfil Escritório de Acordo com Sexo dos Advogados

\begin{tabular}{l|c|c|c}
\hline \multirow{2}{*}{} & \multicolumn{2}{|c|}{ SEXo } & TOTAL \\
\cline { 2 - 4 } ATÉ 9 ADVOGADOS & MASCULINO & Feminino & 54 \\
\cline { 2 - 4 } DE 10 A 49 ADVOGADOS & $53,7 \%$ & $46,3 \%$ & 92 \\
50 OU MAIS ADVOGADOS & $42,4 \%$ & $57,6 \%$ & 70 \\
\hline
\end{tabular}

TABELA 4

Sexo dos Advogados de Acordo com a Filiação do Escritório (Cesa e não Cesa)

\begin{tabular}{l|c|c|c}
\hline \multirow{2}{*}{ NĀo CESA } & \multicolumn{2}{|c|}{ SeXo } & Total \\
\cline { 2 - 4 } CESA & Masculino & Feminino & 80 \\
\cline { 2 - 4 } & $48,8 \%$ & $51,3 \%$ & 136 \\
\hline
\end{tabular}


Profissionalização por gênero em escritórios paulistas de advocacia, pp. 265-290

TABELA 5

Cargo Ocupado de Acordo com o Sexo

\begin{tabular}{|c|c|c|c|c|c|}
\hline \multirow[t]{2}{*}{ SEXO } & \multicolumn{4}{|c|}{ CARGO } & \multirow[t]{2}{*}{ TOTAL } \\
\hline & TreineE & AdVOGADO JR. & ADVOGADO SÊNIOR/PLENO & ADVOGADO SÓCIO & \\
\hline MASCULINO & $0,9 \%$ & $31,5 \%$ & $33,3 \%$ & $34,3 \%$ & 108 \\
\hline FEMININO & $0,9 \%$ & $41,7 \%$ & $37,0 \%$ & $20,4 \%$ & 108 \\
\hline
\end{tabular}

TABELA 6

Posição Ocupada de Acordo com Sexo, Segundo o Perfil do Escritório

\begin{tabular}{|c|c|c|c|}
\hline Perfil do Escritório/Sociedade & PosIÇĀO & & \\
\hline \multirow{3}{*}{ ATÉ 9 ADVOGADOS } & \multirow{4}{*}{$\begin{array}{l}\text { NĀo Sócio } \\
\text { Sócio }\end{array}$} & MASCULINO & FEMinino \\
\hline & & $44,8 \%$ & $68,0 \%$ \\
\hline & & $55,2 \%$ & $32,0 \%$ \\
\hline TOTAL & & 29 & 25 \\
\hline \multirow[t]{2}{*}{ DE 10 a 49 ADVOGADOS } & NĀo SÓCIO & $48,7 \%$ & $77,4 \%$ \\
\hline & Sócio & $51,3 \%$ & $22,6 \%$ \\
\hline TOTAL & & 39 & 53 \\
\hline \multirow[t]{2}{*}{50 OU MAIS ADVOGADOS } & NĀo SóCIO & $97,5 \%$ & $93,3 \%$ \\
\hline & Sócio & $2,5 \%$ & $6,7 \%$ \\
\hline TOTAL & & 40 & 30 \\
\hline
\end{tabular}

TABELA 7

Faculdade em que se Bacharelou de Acordo com Sexo

\begin{tabular}{|c|c|c|}
\hline \multirow[t]{2}{*}{ FACULDADE } & \multicolumn{2}{|c|}{ SEXo } \\
\hline & Masculino & FeMinino \\
\hline USP & $25,5 \%$ & $17,8 \%$ \\
\hline PUC & $30,2 \%$ & $31,8 \%$ \\
\hline MackenZle & $8,5 \%$ & $17,8 \%$ \\
\hline FMU & $10,4 \%$ & $15,9 \%$ \\
\hline UNIP & $5,7 \%$ & $4,7 \%$ \\
\hline OUtRas Particulares & $16,0 \%$ & $11,2 \%$ \\
\hline OUtras Públicas & $3,8 \%$ &, $9 \%$ \\
\hline TOTAL & 106 & 107 \\
\hline
\end{tabular}


TABELA 8

Faixa de Rendimento por Sexo, de Acordo com o Perfil do Escritório

\begin{tabular}{|c|c|c|c|}
\hline \multirow[t]{2}{*}{ Perfil do Escritório/Sociedade } & \multirow[b]{3}{*}{ Até $\mathrm{R} \$ 2000$} & \multicolumn{2}{|c|}{ SEXO } \\
\hline & & MASCULINO & FEMININO \\
\hline \multirow[t]{8}{*}{ ATÉ 9 ADVOGADOS } & & $24,1 \%$ & $16,0 \%$ \\
\hline & Mais de $\mathrm{R} \$ 2000$ a $\mathrm{R} \$ 4000$ & $34,5 \%$ & $48,0 \%$ \\
\hline & Mais de $\mathrm{R} \$ 4000$ a $\mathrm{R} \$ 6000$ & $10,3 \%$ & $12,0 \%$ \\
\hline & Mais de $\mathrm{R} \$ 6000$ a $\mathrm{R} \$ 8000$ & $6,9 \%$ & 0 \\
\hline & Mais de $\mathrm{R} \$ 8000$ a $\mathrm{R} \$ 10000$ & 0 & $12,0 \%$ \\
\hline & Mais de $\mathrm{R} \$ 10000$ a $\mathrm{R} \$ 12000$ & $3,4 \%$ & $4,0 \%$ \\
\hline & Mais de $\mathrm{R} \$ 12000$ & $13,8 \%$ & 0 \\
\hline & Não revelada & $6,9 \%$ & $8,0 \%$ \\
\hline TOTAL & & 29 & 25 \\
\hline \multirow[t]{8}{*}{ DE 10 A 49 ADVOGADOS } & Até $\mathrm{R} \$ 2000$ & 0 & $11,3 \%$ \\
\hline & Mais de $\mathrm{R} \$ 2000$ a $\mathrm{R} \$ 4000$ & $25,6 \%$ & $41,5 \%$ \\
\hline & Mais de $\mathrm{R} \$ 4000$ a $\mathrm{R} \$ 6000$ & $7,7 \%$ & $15,1 \%$ \\
\hline & Mais de $\mathrm{R} \$ 6000$ a $\mathrm{R} \$ 8000$ & $20,5 \%$ & $11,3 \%$ \\
\hline & Mais de $\mathrm{R} \$ 8000$ a $\mathrm{R} \$ 10000$ & $15,4 \%$ & $5,7 \%$ \\
\hline & Mais de $\mathrm{R} \$ 10000$ a $\mathrm{R} \$ 12000$ & $12,8 \%$ & 0 \\
\hline & Mais de $\mathrm{R} \$ 12000$ & $15,4 \%$ & $9,4 \%$ \\
\hline & Não revelada & $2,6 \%$ & $5,7 \%$ \\
\hline TOTAL & & 39 & 53 \\
\hline \multirow[t]{8}{*}{50 OU MAIS ADVOGADOS } & Até $\mathrm{R} \$ 2000$ & $5,0 \%$ & $16,7 \%$ \\
\hline & Mais de $\mathrm{R} \$ 2000$ a $\mathrm{R} \$ 4000$ & $32,5 \%$ & $30,0 \%$ \\
\hline & Mais de $\mathrm{R} \$ 4000$ a $\mathrm{R} \$ 6000$ & $27,5 \%$ & $10,0 \%$ \\
\hline & Mais de $\mathrm{R} \$ 6000$ a $\mathrm{R} \$ 8000$ & $15,0 \%$ & $10,0 \%$ \\
\hline & Mais de $R \$ 8000$ a $R \$ 10000$ & $2,5 \%$ & $3,3 \%$ \\
\hline & Mais de $\mathrm{R} \$ 10000$ a $\mathrm{R} \$ 12000$ & $5,0 \%$ & $10,0 \%$ \\
\hline & Mais de $\mathrm{R} \$ 12000$ & $12,5 \%$ & $16,7 \%$ \\
\hline & Não revelada & 0 & $3,3 \%$ \\
\hline Total & & 40 & 30 \\
\hline
\end{tabular}

TABELA 9

Instituição em que Advogados se Bacharelaram de Acordo com o Perfil do Escritório e a Posição na Carreira

\begin{tabular}{|c|c|c|c|c|c|}
\hline \multirow[t]{2}{*}{ PosiçĀO } & \multirow[t]{2}{*}{ Perfil escritóRIo } & \multicolumn{3}{|c|}{ INSTITUIÇĀO EM QUE SE GRADUOU } & \multirow[t]{2}{*}{ TOTAL } \\
\hline & & PÚBlica & PRIVADA RELIGIOSA & PrivadA LEIGA & \\
\hline \multirow[t]{3}{*}{ NĀO SÓCIO } & Até 9 advogados & $16,7 \%$ & $30,0 \%$ & $53,3 \%$ & 30 \\
\hline & De 10 a 49 advogados & $8,3 \%$ & $60,0 \%$ & $31,7 \%$ & 60 \\
\hline & 50 ou mais advogados & $35,8 \%$ & $37,3 \%$ & $26,9 \%$ & 67 \\
\hline \multirow[t]{3}{*}{ Sócio } & Até 9 advogados & $20,8 \%$ & $37,5 \%$ & $41,7 \%$ & 24 \\
\hline & De 10 a 49 advogados & $34,4 \%$ & $50,0 \%$ & $15,6 \%$ & 32 \\
\hline & 50 ou mais advogados & $33,3 \%$ & $66,7 \%$ & 0 & 3 \\
\hline
\end{tabular}




\section{Referências Bibliográficas}

BARBALHO, Rennê M. (2008), A feminização das carreiras jurídicas e seus reflexos no profissionalismo. São Carlos. Tese de doutorado. Universidade Federal de São Carlos.

Bergoglio, Maria Inês. (2007), "Llegar a sócia? La movilidad ocupacional em las grandes empresas jurídicas: análisis de gênero”. Centro de Investigaciones Jurídicas y Sociales. Argentina, Faculdad de Derecho, Universidad Nacional de Córdoba.

Bonelli, Maria da Gloria. (2004), "Arlie Russell Hochschild e a sociologia das emoçōes”. Cadernos Pagu, Campinas, 22: 357-372, jan.-jun.

. (2002) Profissionalismo e política no mundo do Direito. São Paulo, EdUFSCar.

Bourdieu, Pierre. (1999), A dominação masculina. Rio de Janeiro, Bertrand Brasil.

Bruschini, Cristina \& Lombardi, Maria Rosa. (2000), "A bi-polaridade do trabalho feminino no Brasil: o emprego doméstico e as 'novas ocupaçōes". Cadernos de Pesquisa da Fundação Carlos Chagas, São Paulo, 110 (1): 67-104.

ButLer, Judith (2003). Problemas de gênero: feminismo e subversão da identidade. Rio de Janeiro, Civilização Brasileira.

CunHA, Luciana G. et al. (2007), "Sociedade de advogados e tendências profissionais”. Revista Direito GV, 6: 111-138, São Paulo.

DAVID, René. (1996), Os grandes sistemas do direito internacional. São Paulo, Martins Fontes.

DeZALAY, Yves e GaRTH, Bryant (2002), The internationalization of palace wars: lawyers, economists, and the contest to transform latin american states. Chicago, The University of Chicago Press.

Galanter, Marc \& Palay, Thomas. (1991), Tournament of lawyers: the transformation of the big law firm. Chicago, The University of Chicago Press.

Galindo, Bruno. (2004), "A teoria da constituição da Common Law: reflexôes teóricas sobre o peculiar constitucionalismo britânico". Revista de Informação Legislativa, 164: 303-316, Brasília.

Granfield, Robert. (1992), Making elite lawyers. Nova York, Routledge.

Guillaume, Cécile. (2007), Les femmes changent-elles le travail? Paris, Presses Universitaires de France.

Heinz, John \& Laumann, Edward. (1982), Chicago Lawyers: the social structure of the Bar. Nova York, Russell Sage Foundation e Chicago, American Bar Foundation. Hirata, Helena \& Kergoat, Danièle. (2003), "A divisão sexual do trabalho revisitada”. In: Maruani Margareth \& Hirata, Helena (orgs.). As novas fronteiras da desigualdade: homens e mulheres no mercado de trabalho. São Paulo, Senac.

JunQUeIRA, Eliane B. (1999), A profissionalização da mulher na advocacia. Rio de Janeiro, Fundação Carlos Chagas. 
Le Feuvre, Nicky Le \& Lapeyere, Nathalie. (2005), "Les 'scripts sexués' de carrière dans les professions juridiques en France”. Knowledge, Work \& Society, 1 (3): 101126, The feminization of the professions: thematic issue. (org. Mirella Giannini).

LEITHÄUSER, Thomas. (2007), "Dominação e reconhecimento nas relações sociais". Conferência apresentada no XIII Congresso Brasileiro de Sociologia. Recife, UFPE. Leuwen, Leny E. de Groot-van. (2003), "Women in the Dutch legal profession (19502000)”. In: Schultz, Ulrike \& SHaw, Gisela (orgs.). Women in the world's legal profession. Oxford, Hart Publishing, pp. 341-351.

Nelken, David \& FeEst, Johannes. (2001), Adapting Legal Cultures. Oxford, Hart Publishing.

Ordem dos Advogados do Brasil. (1996), Perfil dos advogados brasileiros. Brasília, Comissão de Ensino Jurídico, OAB.

Piscitelli, Adriana. (2002), “Re-criando a (categoria) mulher?”. In: Algranti, Leila Mezan (org.). A prática feminista e o conceito de gênero. Campinas, Unicamp (col. Textos Didáticos, n. 48), pp. 7-42.

Rubin, Gayle. (2006), “The traffic in women: notes on the 'political economy' of sex". Feminist Anthropology: a reader, no site http://books.google.com.

SCAVOne, Lucila et al. (2006), O legado de Foucault. São Paulo, Unesp.

Sсотт, Joan. (1990), "Gênero: uma categoria útil para a análise histórica”. Revista de Educação e Realidade (Gênero e Mulheres), 2 (16): 5-22, Porto Alegre.

Schultz, Ulrike \& SHAw, Gisela (orgs.). (2003), Women in the world's legal professions. Oxford, Hart Publishing.

\section{Resumo}

Profissionalização por gênero em escritórios paulistas de advocacia

$\mathrm{O}$ artigo analisa as diferenças na profissionalização de advogados e advogadas, em uma amostra de 216 jovens profissionais de escritórios de São Paulo. Mostra como o profissionalismo e as relações de gênero se articulam na estratificação da advocacia, com carreiras marcadas pelo "script sexuado", quanto a ser sócio(a) ou associado(a), quanto ao tamanho do escritório onde atuam (pequeno, médio ou de grande porte) e a clientela que representam prioritariamente (individual ou empresarial).

Palavras-chave: Profissionalização; Advogadas; Advogados; Gênero; Carreira. 


\section{Abstract}

\section{Gendered careers in São Paulo law firms}

The article analyzes the differences in the professionalization of men and women lawyers in a survey of 216 young professionals from São Paulo law firms. It shows how professionalism and gender relations combine to stratify legal practice and differentiate careers according to a 'sexed script,' whether in terms of being a partner or an associate, or in terms of the size of the firm where people work (small, medium or large) and the main clients they represent (individuals or companies).

Keywords: Professionalization; Men and Women Lawyers; Gender.

Texto recebido em 13/

$07 / 2007$ e aprovado em 22/02/2008.

Maria da Gloria Bonelli é doutora em Ciências Sociais pela Unicamp e professora titular do Departamento de Sociologia da UFSCar. E-mail: qbon elli@uol.com.br.

Luciana Gross Cunha é doutora em Ciência Política pela USP e professora da Escola de Direito de São Paulo da Fundação Getúlio Vargas. E-mail: luciana cunha@fgvsp.br.

Fabiana Luci de Oliveira é doutora em Ciências Sociais pela UFSCar e pesquisadora da Ipsos Public Affairs. E-mail: luci.oliveira@ipsos.com.br.

Maria Natália Barboza da Silveira é mestranda do Programa de PósGraduação em Ciências Sociais na UFSCar. Email: naty_silveira9@h otmail.com. 